\title{
RBEP
}

\section{Docência em História: implicações das novas disposições curriculares do ensino médio}

Nilton Mullet Pereira

Fernando Seffner

Carmem Zeli Gil

Carla Meinerz

\section{Resumo}

Trata-se de um exercício de escrita inédito, resultado de reflexões realizadas pelo grupo de professores da área de ensino de História sobre o tema do ensino médio. A preocupação central é compreender o processo de mudanças no ensino médio propostas pelo Ministério da Educação (MEC) e pelos governos estaduais, na perspectiva do ensino de História. Abordamos quatro enfoques conceituais e teóricos: o primeiro refere-se à própria compreensão dos processos de mudanças propostos e sua relação com o ensino de História; o segundo refere-se à centralidade da pesquisa, que assume um caráter de operador estratégico do princípio da interdisciplinaridade e da contextualidade; o terceiro consiste na compreensão do papel dos agentes principais do ensino médio, que são os jovens e as culturas juvenis; o quarto diz respeito ao tema da memória e do patrimônio, uma vez que o ensino de História consiste em um movimento de criação/recriação da memória histórica.

Palavras-chave: ensino médio; ensino de História; pesquisa. 


\section{Abstract \\ Teaching history: implications of the new curricular provisions for high school}

The article is an unprecedented exercise in writing, a result of reflections made by a group of professors in the area of history teaching, on the topic of high school. The central concern is to understand the process of change in high school, proposed by the Ministry of Education (MEC) and state governments, in the perspective of teaching history. Thus, we discuss four conceptual and theoretical approaches: the first refers to the understanding itself of the processes of change proposed and their relation to the teaching of history; the second refers to the centrality of the research, which takes on a role as strategic operator of the principles of interdisciplinarity and contextuality; the third consists in understanding the role of the major agents of high school, i.e. the youngsters and their cultures; and the fourth relates to the theme of memory and heritage, since the teaching of history consists of an action of creation/recreation of historical memory.

Keywords: high school; teaching of history; research.

\section{Introdução}

As novas disposições curriculares para o ensino médio no Brasil têm implicações profundas no ensino de História. A proposição oficial sugere um currículo organizado por áreas de conhecimento, com base em dois princípios fundamentais: a interdisciplinaridade e a contextualidade. De um lado, supõe-se uma integração entre as diferentes disciplinas para constituir uma zona de comunicação entre elas; por outro, presume-se o conhecimento enraizado na experiência social de estudantes em idade de inserção no mercado de trabalho e na vida política da cidade. Ambas exigem ampla reflexão por parte dos professores de História, bem como dos outros docentes envolvidos com o ensino médio.

Neste artigo, procuramos, primeiramente, problematizar as novas políticas para o ensino médio, criando uma leitura crítica, que possa avaliar as potencialidades da proposição para o ensino de História. Em um segundo momento, tomamos os princípios da interdisciplinaridade e da contextualidade para pensar a pesquisa como estratégia para o ensino de História e para o ensino médio de modo geral. Em terceiro lugar, resgatamos o tema das culturas juvenis e da juventude como categoria social para compreender o papel da docência em História nos tempos atuais. Finalmente, enfatizamos o aspecto do patrimônio no ensino de História para debater a questão da área das humanidades e os princípios 
do novo ensino médio, sob a ótica da relevância social e política dos bens materiais e imateriais que constituem o caldo cultural no qual a juventude está imersa.

\section{Políticas públicas para o ensino médio}

As propostas que buscam traçar objetivos, conteúdos, estrutura e modos de financiamento do ensino médio formam atualmente um campo de discussão dos mais controversos, no qual se cruzam argumentos por vezes mutuamente excludentes, envolvendo posições políticas, pedagógicas, partidárias, sindicais, culturais e econômicas complexas e antagônicas. Sem dúvida, podemos afirmar que o ensino médio é a "bola da vez" no debate educacional contemporâneo. Todos dão palpites, tudo reverbera fortemente na mídia, a sensação de crise está instalada e, no dizer de muitos atores, o futuro do Brasil depende do modo como se vai encaminhar a gestão desse nível de ensino, o que eleva a temperatura da troca de ideias. Para isso colabora o fato de que, nos demais níveis de ensino, os grandes debates já produziram acordos e pactos nacionais, dando relevo à polêmica referente ao ensino médio. Na educação infantil, nas séries iniciais, no ensino fundamental estruturado em disciplinas, nos programas de educação de jovens e adultos ou na educação no campo e mesmo no ensino superior, atualmente, debate-se sobre questões muito localizadas, pois o consenso em relação a suas macropolíticas já foi atingido, o que não se verifica no caso do ensino médio, em relação ao qual parece que há tudo por fazer.

Diversos outros fatores expandem a polêmica. A maior parte das vagas de ensino médio é ofertada pelas redes estaduais de ensino. ${ }^{1}$ Nessa medida, nos últimos anos os partidos políticos e as coalizões partidárias que governam os Estados aplicaram distintos desenhos curriculares em suas redes escolares e buscam mostrar que tal ou qual alternativa "é a melhor", produzindo uma nítida partidarização no debate (Zibas, 2005). O crescimento econômico brasileiro e a inserção mais vigorosa do País no cenário internacional exigiram mão de obra especializada, tanto em nível universitário, quanto em nível técnico médio, com evidentes impactos na caracterização do ensino médio. A União ampliou consideravelmente seu investimento, aumentando a rede de escolas técnicas federais, ${ }^{2}$ o que tornou visível uma estrutura curricular que associa o ensino médio regular ao ensino técnico em escolas de turno integral. ${ }^{3}$ As necessidades de formação de mão de obra técnica atraíram empresários, banqueiros e fundações mantidas por conglomerados industriais e financeiros - algumas das quais sustentam programas de financiamento para escolas públicas de ensino médio ${ }^{4}$ - para os debates sobre os rumos do ensino médio.

A universalização do ensino fundamental ${ }^{5}$ (com quase cem por cento dos alunos em idade escolar, em todas as regiões brasileiras, matriculados e frequentando a escola), já atingida há pelo menos uma década e hoje quase consolidada, vem trazendo seus impactos sobre o acesso ao

\footnotetext{
1 As informações acerca da matrícula no nível médio de ensino estão disponíveis em numerosas pesquisas. Entretanto, os dados tornamse desatualizados muito rapidamente, pois são objetos de estatísticas anuais. Recomendamos a consulta direta na fonte, em http://portal.inep. gov.br/basica-censo-escolarmatricula (último acesso em 15 de abril de 2013), para verificar, por município, por região ou para o País, as séries estatísticas que comprovam essa afirmação.

2 Um ótimo panorama da expansão e localização da rede de escolas técnicas federais no País pode ser visto em http:// redefederal.mec.gov.br/index. php?option $=$ com content \& view $=$ article\&id $=5 \overline{2} \&$ Itemid $=2$ (último acesso em 15 de abril de 2013). Na base de artigos www. scielo.br podem ser encontrados numerosos textos que analisam esse crescimento.

${ }^{3}$ Sobre a ampliação geral do ensino médio, ver proposições em Goulart; Sampaio; Nespoli, 2006

4 Apenas para exemplificar, recomendamos a visita ao sítio web do Instituto Unibanco, já com tradição na área e enfoque no ensino médio, disponível em http://www.unibanco.com. br/int/hom/index.asp. Mas os interessados em saber mais podem seguir visitando sítios como o da Fundação Telefônica em http://www.fundacaotelefonica. org.br/linhas-de-atuacao/ educacao-e-aprendizagem/ ou do Projeto Pescar em http:// site.projetopescar.org.br/ e as conexões entre programas públicos e empresas, como é o caso do Todos pela Educação, em http://www.gerdau.com.br/meioambiente-e-sociedade/faca-suaparte-todos-pela-educacao.aspx (último acesso em 15 de abril de 2013)

5 Grande quantidade de pesquisas, artigos de jornal e documentos governamentais tratam do tema. Os dados, sempre atualizados, podem ser obtidos em http://portal.inep. gov.br/basica-censo-escolarmatricula (último acesso em 15 de abril de 2013).
} 
ensino médio, pois amplia o número de jovens em condições de seguir os estudos. O regime de cotas sociais para ingresso no ensino superior que contabiliza o tempo de estudo do aluno nas redes públicas de ensino, notadamente no ensino médio - também pressiona o debate. Setores de classe média tradicional, com vistas a facilitar o ingresso de seus filhos nas universidades federais, por meio das cotas nos exames vestibulares de ingresso, buscam vaga em escola pública. Na mão contrária, a ascensão econômica das classes $\mathrm{C}$ e D nos últimos dez anos ocasionou visível crescimento de escolas privadas de ensino médio de baixo custo, situadas em municípios na periferia das grandes cidades, que buscam encantar os filhos dessas famílias recentemente enriquecidas, ofertando um ensino de qualidade duvidosa, mas com a marca do "ensino privado", tido como melhor que o ensino público e um bem de consumo desejado pelas famílias pobres. A situação armou-se de tal modo que tem um componente humorístico, pois famílias de classe média tradicional, que antes frequentavam a escola privada de ensino médio, agora procuram boas escolas públicas, para com isso beneficiar seus filhos no regime de cotas de acesso ao ensino superior federal, aproveitando a folga financeira do não pagamento da escola para investir em cursos de línguas, computação, aulas de reforço etc., ao passo que famílias pobres, antes frequentadoras exclusivas do ensino público, agora matriculam seus filhos em escolas privadas que surgiram para disputar essa fatia de mercado, destinando parte dos novos ganhos para a educação.

Outro elemento sobre esse nível de ensino é a exposição do Brasil no cenário internacional, em particular nas grandes enquetes que confrontam o desempenho e o rendimento educacional entre países. Tradicionalmente, o Brasil tinha tímida participação nos principais levantamentos sobre o assunto. Participava e recebia os resultados, que eram sempre catastróficos, com pouca repercussão na sociedade brasileira, resignada a ver a péssima classificação em termos comparativos. Mas a situação se modificou muito nas recentes décadas. O País estruturou um conjunto de avaliações educacionais de forte efeito e passou a divulgar dados cada vez mais apurados, bem como a participar das respeitadas pesquisas mundiais. ${ }^{6}$ A mudança de partidos políticos no governo central não afetou essa diretriz e os exames nacionais em todos os níveis de ensino só fizeram crescer em importância nos últimos anos, ganhando espaço importante na mídia. Entre as chamadas avaliações de grande impacto está obviamente o Exame Nacional do Ensino Médio (Enem), que mais promove discussão, envolvendo manifestações de empresários e políticos diversos, ao lado dos tradicionais opinantes, como professores, acadêmicos, gestores, afora os veículos de informação. ${ }^{7}$ Vale dizer que são realizadas, a cada ano, várias avaliações educacionais no País (Prova Brasil, Provinha Brasil, Enade etc.), mas é aquela do ensino médio que capitaliza as atenções. Se apresentarmos a um brasileiro, medianamente informado, siglas como Enade, Aneb, Anresc, Saeb, ele não saberá do que se trata e não irá estabelecer a conexão com os sistemas nacionais de 
avaliação do rendimento escolar, mas se falarmos em Enem, certamente o sujeito saberá do significado.

A participação do Brasil nessas avaliações internacionais deriva, em parte, do fato de que as iniciativas em educação estão cada vez mais vinculadas ao debate sobre o desenvolvimento estratégico do País, com base na reiterada afirmação de que vivemos numa sociedade do conhecimento, expressão vaga que serve a muitos propósitos, mas impacta positivamente no valor da educação enquanto um componente importante para o futuro. As propostas educacionais têm seu tom político turbinado nesses tempos e o País passa a ser medido também em termos de desempenho educacional. As pesquisas servem, então, para qualificar práticas, criticar governos, governantes e partidos políticos, causando maior repercussão no País. Atualmente, boa parte da discussão em educação combina argumentos pedagógicos com política educacional.

Muitos exemplos permitem comprovar que a educação é elemento de destaque brasileiro no cenário internacional. A imprensa divulga regularmente a posição e os índices do País. O mais famoso deles, o Índice de Desenvolvimento Humano (IDH), mostra que o Brasil melhora sua posição a cada ano, embora de modo lento e em velocidade inferior a outros países em desenvolvimento. O desempenho educacional do País é sempre um fator a diminuir o crescimento, e quando os resultados são publicados a polêmica reacende. Contudo, a divulgação dos dados em março de 2013 não apenas colocou novamente os avanços em educação no centro dos debates, como fez o Brasil questionar pela primeira vez em sua história os números utilizados pelo Programa das Nações Unidas para o Desenvolvimento (Pnud), encarregado da produção desse indicador. ${ }^{8}$ Além de empresários, educadores, gestores públicos, pesquisadores, diretores de fundações, associações de classe, professores, juízes, as discussões sobre o ensino médio passaram a envolver no Brasil os atores que representam segmentos das Nações Unidas, como PNUD, Organização das Nações Unidas para a Educação, a Ciência e a Cultura (Unesco), Fundo das Nações Unidas para a Infância (Unicef).

A polêmica que envolve o ensino médio não é relativa aos modos de acesso, como no caso do ensino superior, mas refere-se às propostas, às visões de mundo e de pertencimento a distintas filiações em termos pedagógicos e políticos. Os debates acerca do ensino médio têm ajudado a produzir conhecimentos sobre a situação geral da educação no País. As questões são candentes e os frutos da discussão dizem respeito aos rumos da educação nacional. Certamente ainda estamos longe de esgotar o leque de possibilidades para o desenho curricular do ensino médio quando se considera que os alunos, principais interessados, têm sido pouco consultados.

Longe de estabelecer solução para os impasses, investimos no mapeamento da situação conflagrada, apresentando propostas específicas para a disciplina de História. O ensino médio é portador de algumas tensões difíceis de equacionar. Elas aparecem constantemente quando se busca traçar diretrizes de longo alcance. A primeira delas é que se trata
${ }^{8}$ Dados atualizados sobre o IDH e os relatórios e atlas de desenvolvimento humano podem ser encontrados em http://www. pnud.org.br/Default.aspx (último acesso em 15 de abril de 2013). 
de um nível intermediário no qual alunos oriundos do ensino fundamental estão a caminho do ensino superior. Simultaneamente, é nível final de estudos, que encerra ou interrompe por anos a carreira escolar, para grande parcela da população sem condições, interesse ou disposição para cursar uma faculdade.

Desse quase "transtorno bipolar" do ensino médio derivam outras complicações. A principal delas concerne a "preparar para o vestibular" ou "aprender alguma profissão", entre o propedêutico e o técnico. Mesmo aquelas escolas públicas que estruturam o ensino médio para atender as duas demandas paralelamente (por exemplo, com aulas pela manhã do ensino médio regular e aulas à tarde para a formação técnica em alguma profissão) apresentam problemas. Algumas delas passaram a atrair alunos oriundos da classe média, que optam por cursos técnicos vinculados à carreira desejada no ensino superior. Com isso, a vaga originalmente destinada a um aluno de classe pobre, para formar um técnico com boa chance de empregabilidade e ascensão social, passa para o aluno da classe média, que utiliza a escola como trampolim para a universidade, sem que se forme o trabalhador de que o País precisa.

O ensino médio se divide entre formar o cidadão, formar o profissional técnico e formar o bom candidato ao ingresso no ensino superior. Sempre é possível tentar equilibrar as três direções no mesmo desenho curricular, mas isso não é fácil. Se levarmos em conta que é etapa conclusiva para muitos alunos, podemos acentuar a formação cidadã, colocando em discussão temas relativos à produção social das culturas juvenis (que permitam ao jovem entender-se como produto social e histórico de seu tempo), à inserção dos jovens no mundo da política, ao estudo dos rumos culturais e tecnológicos do mundo contemporâneo, à compreensão dos grandes fenômenos globais. Se assumirmos que a prioridade é formar um bom candidato ao ingresso no ensino superior, podemos investir no estudo mais denso das disciplinas (no caso da História, seria o momento de o aluno saber não apenas o que aconteceu, mas como se produz o discurso histórico, abordando tópicos de Teoria da História, de Historiografia, em conexões com a Sociologia, a Filosofia e a Geografia).

Em outras palavras, para que os alunos se reconheçam inseridos em determinadas culturas juvenis, podemos articular o estudo de questões de gênero e sexualidade, raça, etnia, pertencimento religioso, gosto musical, classe econômica, ordem familiar, origem regional, enfim, submeter os pertencimentos sociais e culturais dos próprios alunos a um exame analítico com ferramentas das Ciências Sociais. É difícil conciliar um programa escolar que atenda essa diretriz com aquele que segue os planos de preparação para o ingresso no ensino superior. Se definido que é premente formar um bom técnico, não apenas o conhecimento específico da carreira será necessário, mas também a compreensão das grandes questões que afetam o mundo do trabalho na contemporaneidade, em particular a flexibilização, a precarização, a terceirização, o êxodo para outros países, as dificuldades do primeiro emprego, o desaparecimento 
das tradicionais carreiras etc. Novamente, no desenho da disciplina de História há dificuldades em aliar diferentes propósitos e diretivas.

Entre os desafios já instalados no ensino médio constam as altas taxas de reprovação e evasão, que são muito intricadas de reverter haja vista que fatores plurais concorrem para essa situação e a solução de cada um deles nem sempre aponta para o mesmo formato curricular. Os alunos abandonam esse nível ou não se habilitam nele porque aquilo que se ensina no nível médio não é atraente? A resposta é ensinar coisas que façam sentido em suas vidas de forma mais imediata. Entram os temas ligados às culturas juvenis, saem temáticas atadas a estudos clássicos e a prosseguimento em nível posterior. Temos professores formados para fazer isso? Certamente não e vai demorar para termos. Os alunos desistem porque não aguentam mais estudar tudo de forma obrigatória? Então, a resolução é ofertar parte da carga horária em disciplinas eletivas, nas quais cada um esboce uma porção de seu percurso de estudos? Como ficarão o exame de ingresso ao ensino superior ou o Enem, se alguns candidatos vão fazer escolhas distintas de outros? Há professores preparados para oferecer matérias eletivas? Por exemplo, quem iria lecionar uma disciplina que articule Cinema e História? Temos recursos nas escolas para boas projeções de filmes? Ou vamos querer que, na era da televisão digital e do cinema tridimensional, os alunos fiquem espremidos numa sala abafada, sentados em cadeiras duras, assistindo a longa metragem num aparelho pequeno, equilibrado de modo precário em cima de uma estante, com som vindo de caixas diminutas?

Os alunos abandonam o ensino médio porque não há frequência obrigatória por lei, como é o caso do ensino fundamental, em que a ausência na escola implica acionar o conselho tutelar e punir os pais? Parece simples resolver, bastando legislar e impor o ensino de doze anos, como preceituam as agências das Nações Unidas e acatam países ditos civilizados e desenvolvidos, inclusive vizinhos do Mercosul. Como ficam aqueles que param de estudar porque as famílias precisam do rendimento financeiro do seu trabalho para complementar a arrecadação conjunta? Vamos encaminhar todos ao ensino noturno e fingir que alguém que trabalha o dia todo e estuda à noite poderá chegar ao fim do ano letivo com produtividade similar ao que cursa durante o dia? Simplório seria estender para o ensino médio a Bolsa Escola, já testada e aprovada no nível fundamental. Ocorre que muitos alunos começam a trabalhar não tanto para ajudar no orçamento familiar, mas para ter algum dinheiro próprio, que possa alimentar seus sonhos de consumo, em particular, na produção das identidades juvenis e na inserção em determinadas culturas jovens, todas elas movidas a apelos de aquisição de bens materiais (celular, roupas, bonés, ingresso para shows e festas, tablets, tênis e calçados, aparelhos de som, equipamentos digitais e mais um oceano de coisas impulsionadas pelo mercado). Singelo, ao invés de dar a bolsa para a família, podemos entregá-la ao próprio aluno. Ao contrário do cartão da Caixa Econômica Federal, que é repassado para mãe de estudante no ensino fundamental, forneceremos crédito ao jovem aluno e ele poderá gastar no que quiser 
o dinheiro público ali destinado, desde que se mantenha estudando e frequentando a escola. Sem esforço, imaginamos a polêmica que se instalaria na mídia acerca disso. Não faltarão acusações de que os alunos irão despender em drogas, festas e bailes funk, roupas sexualmente provocantes, lanches tipo fast food, extravagâncias. Outros poderão dizer que o financiamento dado aos alunos pode lhes ensinar o valor do dinheiro e da organização monetária. A experiência do microcrédito no Brasil e no mundo mostra que os mais pobres são mais ajuizados no gasto do dinheiro público e mais preocupados com o pagamento das dívidas contraídas.

No meio de tantas tensões, nossas proposições, que vêm a seguir neste texto, podem parecer um "curativo" posto sobre uma perna gangrenada. Acreditamos que parte da solução para esses impasses vem do raciocínio das disciplinas, dos modos de ensino aplicados em sala de aula. No nosso caso, contribuímos com reflexões extraídas do ensino de História, das práticas cotidianas e dos conhecimentos acumulados em pesquisas e acompanhamentos de estágios por muitos anos. Não se trata de esperar que os gestores e intelectuais façam o delineamento das macropolíticas, para depois pensar o que vamos fazer em nossa sala de aula. ${ }^{9}$ Podemos desde já avançar em proposições para o trabalho docente em História.

\section{Pesquisa e docência em História}

O ensino médio é um nível de escolarização no qual os estudantes podem ter um profundo envolvimento com o seu mundo, ou seja, com o espaço político da cidade (Pereira; Seffner, 2008). Em quaisquer dos turnos, da manhã à noite, o professor de História do ensino médio se depara com jovens inseridos no mundo do trabalho e no mundo da política. Tudo se passa como se, nesse momento, o indivíduo se dispusesse numa situação social que lhe obriga a atuar não apenas como aprendiz, mas como agente nas interações sociais

Por essa razão, pensar o ensino nesse nível é voltar-se à pesquisa. Os princípios que regem o novo ensino médio, ainda que resgatem disposições bastante conhecidas dos estudos e das discussões educacionais, parecem estar perfeitamente adequados a um operador estratégico que é a pesquisa. Tanto a interdisciplinaridade quanto a contextualidade exigem, cada um a seu modo, que os estudantes desenvolvam a pesquisa como instrumento pedagógico por excelência. A Resolução CNE/CEB nº 2/2012 estabelece claramente o trabalho e a pesquisa como "princípios educativos e pedagógicos, respectivamente". ${ }^{10}$

Professores de História certamente têm presente em suas

Recomendamos a leitura de Moehlecke (2012) e Kuenze (2010) sobre as tensões citadas.

${ }^{10}$ Resolução CNE/CEB 2/2012. Diário Oficial da União, Brasília 31 de janeiro de 2012, Seção 1, p. 20 . lembranças a prática da pesquisa no âmbito dessa disciplina. A rigor, nossa memória se prolonga a períodos de um devir-aluno, nos quais se propunha pesquisa sobre determinado tema: "pesquise sobre as causas da Revolução Francesa". A resposta a essa solicitação não era outra senão um extenso texto escrito à caneta, que preenchia meia dúzia de páginas 
de folha de papel almaço. Ainda hoje se verifica a tão enfadonha proposta de investigação que leva o estudante a recolher páginas da Wikipedia, imprimir e depositar sobre a mesa do professor. Por muito tempo a pesquisa nas aulas de História foi isso: uma bela capa e um longo texto copiado do livro didático ou retirado da internet. Então, seria o caso de perguntar, afinal de contas, em que consiste a pesquisa no ensino médio, na aula de História?

Ora, já afirmamos que o ensino médio é um nível de escolaridade em que os estudantes já dispõem de instrumentos que os tornam capazes de interagir na sociedade, na vida pública e no chamado mundo do trabalho. Além disso, o estudante do ensino médio insere-se no mundo da leitura e da escrita, que não é simplesmente dos códigos e dos símbolos que compõem o seu universo social, mas uma leitura conceitual do mundo, do seu mundo e do mundo dos outros; uma escrita conceitual da vida - da sua e das alheias. Eis que se introduzem na esfera do ensino de História na escola média seus elementos vitais: escrita e leitura conceitual do mundo.

Nesse sentido, pode-se muito bem ter como um operador estratégico a pesquisa que carregue como efeito a escrita e a leitura, como se escrever e ler fosse um belo e inusitado encontro com a vida, sua atualidade e a névoa que a circunda.

Se efetivamente a pesquisa não pode ser reduzida à dissertação ou à transcrição de um texto, em que consiste isso que chamamos de um operador estratégico? Em primeiro lugar, no problema. O problema é que os problemas são velhos. O problema é que nos deixamos tocar por problemas já prontos, feitos, moldados, cansados, exageradamente fixados no nosso cotidiano - um lugar-comum dos lugares-comuns. Assim, por anos, temos buscado soluções. Uma pesquisa, na escola básica e na aula de História, não consiste em uma resposta, um problema que é exterior a sua própria resolução. Digamos que pesquisar consiste em criar problemas, de modo que, ao invés de vasculhar soluções, tenhamos coragem de criar problemas para tornar mais surpreendente nossa sala de aula de História.

Quando vamos fechar a porta para os problemas já formados? Fechar a porta para a cópia da Wikipedia, para a pergunta sobre as causas da Guerra dos Farrapos e para toda a sorte de questões que falam tão pouco ao coração - que tão pouco nos fazem ter sensações, que sempre entram pelo lado avesso da intuição. São esses problemas já criados que enfadam a aula de História no ensino médio e tão pouco tocam a vida.

O problema hoje é não dar soluções, mas criar novos problemas. Eis a linha, a força dos problemas incriados, à espera de um novo encontro para aparecer e se colocar no interstício do nosso mal fadado cotidiano, nosso lugar de conforto e comunhão. Deixar-se desconcertar por forças ainda não catalogadas e codificadas no universo de uma aula de História é o que os novos problemas nos prometem.

Criar problemas tem a ver com esquecimento, uma vez que se nega a própria história, se contrapõe solenemente à memória. Abandona o lugarcomum da ordem, despede-se de pleno da gramática cotidiana da escola (das causas, das identificações, das consequências, dos principais líderes), 
conjunto de regras que constroem uma memória que leva estudantes todos os dias a "repetir o repetitório", andar sobre o "já-dito", sem desconfiar do tom seco e amorfo dessa gramática.

Pesquisar é, no ensino médio e na aula de História, criar problemas, colocar problemas, como resultado de um encontro inaudito entre o conteúdo proposto pelo professor e as necessidades da vida de cada estudante. Um problema forma-se, constitui-se e aparece quando um encontro ocorre entre vida e história escrita. É claro que pensar o conteúdo na sua relação com a vida e com a expansão da vida tem a ver com o princípio da contextualidade, mas não se trata de simplesmente aproximar o contexto, as agruras, as questões do cotidiano do conteúdo de História, mas de fazer o conteúdo da disciplina debater com esse cotidiano, problematizá-lo, desacomodá-lo e deixar o estudante andar por caminhos ainda não trilhados por ele. Expandir a vida é, desse modo, abandonar um pouco o próprio cotidiano. A História pode bem se prestar a criar problemas para que isso aconteça, uma vez que é na diferença e não na semelhança que ela nutre os programas, os currículos, e é ao debater com o estranho que o estudante pode, por fim, criar problemas, pesquisar, transfigurar-se.

Propor a pesquisa no ensino médio, em História, é ensinar a criar problemas, a perguntar para uma fonte, uma imagem, uma música, uma charge, um poema, um fragmento, uma crônica. As perguntas feitas não decorrem de respostas, mas de forças que habitam o vazio em torno de cada acontecimento ou de cada documento. Pesquisar torna-se uma arte, uma arte de criar problemas, de fazer perguntas e de improvisar respostas. É como perguntar "como é possível supor que tantos tenham aceitado e seguido as ideias de Hitler?" ou "como pôde uma mulher liderar um movimento messiânico numa colônia alemã, no sul do Brasil?"; ou, ainda, "como pôde ser o nazismo um fenômeno da sociedade liberal, uma vez que se tratava de um regime totalitário?". Puras perguntas, que de sua pureza podem sugerir problemas que se desdobram sobre suas respostas, jamais encontradas em um longo texto copiado do livro didático ou "baixado" da Wikipedia. Com maior ou menor complexidade, perguntar torna-se uma arte, uma arte de fabular o passado, de criar um jogo que brinca com as hipóteses levantadas e afirmadas pelos historiadores. Aqui a ciência tem o seu limite, a própria escrita da História tem o seu limite. É na sala de aula que a escrita da História encontra seu limite, e a fabulação é o modo como professores da disciplina ruminam as afirmações e as hipóteses criadas no âmbito da pesquisa histórica. A sala de aula é o lugar de fabricação de disposições que permitem uma entrada no passado, uma imersão no tempo, uma verdadeira viagem em direção à imaginação, quebrando regras, desafiando a cronologia dos acontecimentos, expondo a fragilidade de suas causas. Aprender com a pesquisa tornou-se uma fabulação, na medida em que chegar à verdade se dá pelos caminhos do jogo e da imaginação, pela ousadia de duvidar das afirmações da ciência, problematizá-las, ou seja, colocá-las na forma de problemas. 
Há também o conceito. Pergunta-se o que se faz quando se ensina História no ensino médio e a resposta, por regra, é a suposição de um aprofundamento nas reflexões feitas no ensino fundamental. Mas cremos que, no ensino médio, tal imersão não se mostra pela quantidade maior de informações ou pela complexidade do próprio objeto de ensino, mas pela introdução da força dos conceitos na aula de História. A entrada dos conceitos é triunfal, flamejante e sempre produtora de aprendizagens novas, pois o conceito é criação, não apenas definição, mas armadura. O instrumental estoico para a vida. Os conceitos tornam-se instrumentos da própria vida, para um movimento de expansão da vida.

Digamos que no ensino médio se aprende. Melhor, cria-se na medida em que se aprendem os conceitos históricos. É o tempo das interações sociais no qual a juventude se encontra com os domínios políticos e produtivos da cidade. Para tal, os conceitos históricos se apresentam como operadores e como lugares de criação da vida. Armar-se de conceitos, de logos, para enfrentar o mundo do político e o mundo do trabalho. Nesse sentido, a pesquisa é o lugar da aprendizagem e da criação dos conceitos. Tendo por fundamento a pergunta "como pôde ser o nazismo um fenômeno da sociedade liberal, uma vez que se tratava de um regime totalitário?", é possível fabular sobre os conceitos de liberalismo, totalitarismo, nazismo. E assim a pesquisa é um operador estratégico para aprender e para criar, num processo que é inteiramente da cena escolar, o conceito.

A pesquisa no ensino médio, como resposta às exigências desse tempo da juventude, opera com a pergunta-problema e com o conceito, no sentido de, por meio de um movimento de fabulação, no limite da ciência histórica - já que ela se mostra incapaz de ensinar o conceito na sala de aula da escola básica -, levar a efeito um processo de recriação dos conceitos históricos, necessários para constituir a armadura de enfrentamento da vida - sina da juventude. Pesquisar é mais do que aprender conceitos, consiste em movimentar os conceitos para dar conta de uma dada realidade. É assim que o ensino médio se revela como o espaço por excelência no qual se permite que os estudantes recriem conceitos e se coloquem a movimentá-los por meio de uma atividade de pesquisa.

O articulador estratégico que é a pesquisa, no ensino médio, apresenta-se como a construção de um problema que possibilita a movimentação dos conceitos históricos. Pesquisar é operar com os conceitos: uma vez que se criaram e se recriaram os conceitos de liberalismo e de nazismo, nesse processo fabulatório que é a aula de História pode-se, ao responder a pergunta "como é possível supor que o nazismo seja um fenômeno da sociedade liberal?", operar com os conceitos para responder a pergunta. O interessante desse processo é que a própria aprendizagem desses conceitos permite a operação. A sala de aula torna-se um espaço de experimentação, segundo o qual se provocam acontecimentos, se elaboram problemas, se criam conceitos e se fabula para ensinar História. Podemos pensar em uma aula de História que se proponha a pesquisar as relações entre o Ocidente e o Oriente, 
de modo que se provoque a pergunta: "o que é um oriental?" ou "como o Ocidente criou a ideia de Oriente?". Trata-se de propor a pesquisa que crie a pergunta e situar na ordem da resposta a construção do conceito. Nesse caso, temos o conceito de Oriente no centro do problema; dar conta desse conceito implica compreender como criamos, no Ocidente, uma definição de Oriente. Um projeto de pesquisa desse tipo pode muito bem propor a análise de fragmentos de filmes que possam ser disparadores para a construção do conceito, a fim de dar conta do problema. Duas imagens mostram-se interessantes nesse caso: o diálogo entre Leônidas e Xerxes, no filme $300^{11}$ e a entrega do Oscar pela primeira-dama dos Estados Unidos ao diretor Ben Affleck, do filme Argo. ${ }^{12}$ Duas imagens que permitem problematizar as relações Ocidente e Oriente e pensar sobre o modo como, no Ocidente, temos criado uma ideia de oriental.

O exemplo que mostramos acima, que inclui a utilização do recurso audiovisual, constitui um problema e propõe movimentar um conceito. Tal prática, que pode ser na forma de um projeto ou parte do cotidiano da sala de aula de História, é o que cria ferramentas para o jovem poder ler e escrever o seu mundo e o mundo dos outros, a sua vida e a vida dos outros.

\section{Estudar História com os jovens que estão no ensino médio}

Estudar História pode proporcionar múltiplas experimentações, dentre as quais destacamos a possibilidade de desenvolver um olhar complexo para as questões vividas por diferentes homens e mulheres, habitantes de outros tempos e espaços, para seus modos de agir, sentir e pensar. Esse olhar carrega a perspectiva de nossos próprios anseios e faz do encontro com a pluralidade uma das paixões que a História desperta, contendo o potencial da criação de problemas interessantes para a pesquisa na educação escolar. Da mesma forma, o ensino de História na contemporaneidade agrega uma diversidade de ações e sentidos, que se baseia na interação entre diferentes atores sociais que nele se envolvem, constituindo-se numa polifonia de vozes advindas de educadores, estudantes, comunidades, gestores públicos e intelectuais, entre outros.

Para os jovens que estão no ensino médio, a História pode igualmente proporcionar o confronto com a multiplicidade de experiências juvenis no Brasil, marcada pela diversidade cultural e pela desigualdade. Propomos pensar o ensino de História na perspectiva de seus jovens alunos, tematizando quem são esses meninos e meninas que chegam nessa etapa da escolarização, qual sua cultura, seus sonhos e suas interrogações. Mudamos o centro da reflexão, passando da educação escolar para os sujeitos jovens, reconhecendo que o ensino de História também deve ser reconsiderado, tendo por base os desafios que a juventude nos coloca.

A maioria dos estudos fundamentados na Sociologia e na Antropologia

11 300, dirigido por Zack Snyder 2006, Warner Bros., EUA.

${ }^{12}$ Argo, dirigido por Ben Affleck, 2012, Warner Bros., EUA. Oscar de melhor filme em 2013 atenta para o fato de não podermos mais falar em juventude sem abordar a questão da diversidade. A incongruência de construir uma definição homogênea dessa categoria vem sendo apontada por muitos autores 
brasileiros no campo da educação, entre eles Sposito (2001) e Dayrell (2001), que inovaram ao vislumbrar o jovem para além da condição de aluno. A compilação desses estudos, feita por Marília Sposito (2001), demonstra que, por algum tempo, privilegiou-se a pesquisa do jovem na condição de aluno, restringindo-se a ação investigativa ao interior da escola. Numa nova apresentação, crescem os estudos focados nos jovens em seus processos de socialização e sociabilidades, baseando-se no mundo da cultura, da formação de grupos artísticos, religiosos, políticos, da associação por intermédio de gangues ou tribos, enfim, das mais diversas identificações, manifestas em diferentes formas de viver a juventude.

O debate em torno das temáticas das culturas juvenis e da juventude como categoria social é fundamental para a compreensão do papel da docência em História nos tempos atuais. Provoca a olhar e escutar os jovens em suas questões, compreendendo-os como pessoas que estão às voltas com a vida, representantes de uma forma de viver a juventude em tempos e espaços que lhes são próprios, incita a pensar que não são sujeitos que apenas experimentam uma fase da vida que irá passar, mas vivenciam conosco, de forma peculiar, seus processos indissociáveis de constituição histórica, individual e social. A relação que estabelecemos com nossos jovens alunos é pautada pelos nossos próprios aprendizados e interrogações em relação às tensões da vida e aos conhecimentos aí produzidos.

Fabbrini e Melucci (2004), em suas pesquisas com jovens de Milão (Itália), abordam a juventude como um momento em que os aprendizados e as experimentações, especialmente aqueles relativos às possibilidades de mudanças, incidem de forma importante nos processos vitais seguintes. Para os autores, a transformação contínua e a capacidade de enfrentá-la é um recurso exigido de cada adulto para mover-se na experiência social, baseado no que se viveu na juventude.

A mudança e a possibilidade de pensá-la são características fundamentais para compreender a juventude como categoria social e, ao mesmo tempo, podem ser elementos potencializadores do encontro com as múltiplas experimentações dos estudos da História na escola. O corpo, a ética, a estética, o pensamento, as relações sociais são elementos em transformação na juventude, pois nessa fase é socialmente desejado que se comece a responder: quem sou eu? quem devo ser? quem posso ser? Tais questões são propulsoras de sonhos e projetos de futuro, igualmente atravessadas pelos contextos socioculturais em que cada sujeito se insere, pelas demandas familiares, de trabalho e de escolarização. São exigências que colocam os jovens no mundo da política e das relações sociais mais complexas. Surge o deslocamento da análise que antes tratava a juventude como problema e agora a situa como sintoma social e principal vítima da sociedade em que se desenvolve. Alguns dados lançados pelas pesquisas constitutivas do Mapa da Violência no Brasil/2012 evidenciam a crescente vitimização dos jovens brasileiros. São eles que morrem em maior quantidade por acidentes de trânsito ou assassinados. A desigualdade socioeconômica, que caracteriza nosso País, constrói cenários em que os 
jovens empobrecidos, no campo e na cidade, vivenciam formas frágeis e insuficientes de inclusão.

Com base nessa breve reflexão sobre a juventude como categoria social e as culturas juvenis, podemos redimensionar os desafios do ensino médio em nosso País, que tem difícil relação com os projetos de futuro dos jovens brasileiros.

Enfrentamos alguns dilemas na educação em geral e no ensino médio, em específico, pautadas por uma crise da função social da escola na contemporaneidade. Destacamos o fato de que muitos jovens não estão tendo acesso a essa etapa da escolarização em nosso País. Segundo estudos divulgados pelo Ministério da Educação em 2008, no documento "Reestruturação e Expansão do Ensino médio no Brasil", produzido pelo Grupo de Trabalho Interministerial instituído pela Portaria n ${ }^{\circ} 1.189$ de 5 de dezembro de 2007 e pela Portaria no 386 de 25 de março de 2008, atualmente mais de 50\% dos jovens de 15 a 17 anos não estão matriculados na educação básica e milhões de jovens com mais de 18 anos e adultos não concluíram o ensino médio, configurando uma grande dívida da sociedade com parte de sua população. A análise dos dados da Pesquisa Nacional por Amostra de Domicílios (Pnad) do IBGE (2011) reforça que a passagem dos anos não alterou tal situação, indicando que apenas 51,6\% dos garotos entre 15 e 17 anos frequentavam o ensino médio naquele ano. Tais jovens apresentaram uma taxa de escolarização de 83,7\%, um pouco maior se comparada a 2001 (81\%) quando somente 36,9\% dessa faixa etária estava no ensino médio, revelando alta defasagem idade/série.

Os jovens que ainda permanecem no ensino médio vivem uma situação precária em relação à permanência e à aprendizagem, incorrendo em evasão, especialmente nas escolas públicas, e apresentam dificuldades em conectar-se com as proposições da educação escolar. Tais questões resultam da própria falta de clareza acerca do papel dessa etapa da escolarização e da importância do nível médio, seguinte ao ensino fundamental, e de sua relação com o mercado de trabalho, com o ensino superior e com a formação pensada em termos mais amplos, relacionada às noções de autonomia e cidadania. Esse mesmo estudo propõe uma reestruturação do modelo pedagógico que colabore na superação do dualismo entre o ensino propedêutico e o ensino profissional.

Diante disso, o Ministério da Educação, por meio da Resolução CNE/ CEB $n^{\circ} 2$, de 30 de janeiro de 2012, definiu as diretrizes curriculares nacionais para o ensino médio. Salientamos o artigo quinto do capítulo dois, que estabelece como base legal e conceitual de oferta e organização do ensino médio o "reconhecimento e aceitação da diversidade e da realidade concreta dos sujeitos do processo educativo, das formas de produção, dos processos de trabalho e das culturas a eles subjacentes". Embora o texto, em geral, pouco utilize o conceito de juventude, vemos aqui uma brecha para que se prossiga a provocação que aqui iniciamos em relação ao tema da juventude e do ensino de História no ensino médio. Ela está conectada com o princípio da contextualidade, dentro da argumentação anterior que reconhece a necessidade de o conteúdo 
de História debater com o cotidiano, problematizá-lo, desacomodá-lo, deixando o estudante andar por caminhos ainda não trilhados.

Numa sociedade marcada pela desigualdade socioeconômica, as perspectivas e os projetos futuros tornam-se marcadamente construídos em trajetórias individuais de seus jovens, credores de uma dívida social imensa, impelidos a responder às perguntas da juventude: "quem são? o que querem ser? o que podem ser?" Provas de vestibulares, exames nacionais, fichas de emprego, apelos da contravenção, são parte do conjunto de problemas a serem enfrentados pela juventude brasileira. Por vezes, tais exigências sociais afastam o jovem das proposições curriculares da escola. É o caso do sujeito que evade da escola em função de demandas de trabalho ou, ainda, do estudante que se interessa apenas pelos ditames de concursos e provas que lhe são exigidos para a continuidade dos estudos e a construção de um percurso profissional. Como estudar História com esses jovens? As possíveis respostas não serão construídas sem o debate aberto e a participação de seus protagonistas: jovens/estudantes e adultos/ professores. Isso implica desacomodar-se.

O ensino de História pode proporcionar o desenvolvimento de um olhar complexo, com as indagações e o aparato conceitual específico dessa área. Trata-se de mirar a humanidade e suas questões presentes e passadas. Fazer parte do grupo de especializações que chamamos de Ciências Humanas é o primeiro elemento que podemos destacar na proposição das diretrizes curriculares nacionais para o ensino médio. É preciso atentar, porém, para que essa proposta mantenha o espaço e o princípio de cada área nos momentos em que nos desafiamos a praticá-la em nossos cotidianos educativos. Os anseios e devaneios da juventude, vividos na pluralidade contemporânea de experimentações e criações das culturas juvenis, podem tornar-se um problema interessante de pesquisa no campo das Ciências Humanas em geral e da História, em específico. Isso possibilita a criação de perguntas, por exemplo, sobre como viviam jovens em outros tempos e espaços, quais eram seus fazeres e saberes, seus conceitos e preconceitos.

Outro elemento que ressaltamos está conectado ao combate às diversas formas de intolerância, de racismo e de xenofobia que se tornaram pauta de muitas agendas políticas dentro e fora de nosso País, com repercussões no campo educacional e no ensino de História. A Lei $\mathrm{n}^{\mathrm{0}}$ 10.639/03, modificada pela Lei $\mathrm{n}^{\circ} 11.645 / 08$, incluiu a obrigatoriedade do ensino de História e cultura afro-brasileira, africana e indígena no currículo escolar, promovendo uma formação sobre as relações étnicoraciais na educação básica. Os desafios em contemplar e experimentar essas temáticas no cotidiano escolar estão relacionados com a perspectiva de inserção dos jovens no âmbito da política e das relações sociais próprias ao mundo adulto, exigindo novamente uma busca de compreensão da sociedade em que se situam, aqui destacadamente marcada pela multiculturalidade e pela desigualdade. Reincidimos em falar do ensino de História como propulsor de olhares que carregam a perspectiva de nossas próprias questões, despertando uma paixão pelo encontro com a 
pluralidade. São olhares instrumentalizados pela pesquisa e orientados por docentes instigados em proposições criativas de ensino.

Quando reconhecemos o sujeito jovem em sua pluralidade também podemos reconhecer que não apenas ensinamos para ele, mas estudamos com ele, interrogamo-nos e encaramos, de forma conjunta, a perplexidade diante das questões históricas e sociais.

\section{O patrimônio e a pesquisa na aula de História}

O ensino de História já serviu a muitos propósitos, desde um conhecimento usado pelos governantes para configurar uma visão do passado que pudesse fortalecer sentimentos patrióticos até um saber útil para exibir em conversas, evidenciando a virtude intelectual de uma boa memória. Hoje, na esteira de diferentes concepções e abordagens, buscamos construir outros jeitos de ensinar História, problematizando-a como conhecimento pronto e cheio de ideias conclusivas. Nessa perspectiva, novos tópicos ou releituras de temas clássicos entram em cena no currículo escolar. Um deles é o patrimônio. Polêmico por servir a "muitos senhores", é um assunto que tem potencialidade para promover situações de pesquisas no ensino médio, colocando os jovens em contato com as manifestações, realizações e representações do Brasil e de outros países. Também possibilita tramar questões em investigações sobre a memória nacional, como as práticas culturais de povos de outros continentes. Ensino de História e pesquisa: o que tudo isso tem a ver com patrimônio?

Em 2009, o Ministério da Educação apresentou o programa Ensino Médio Inovador, pretendendo superar a dualidade histórica desse nível de ensino ao incorporar o caráter propedêutico e de preparação para o trabalho. A intenção foi a articulação interdisciplinar, por áreas de conhecimento, com atividades integradoras definidas com base em quatro grandes temas: trabalho, ciência, tecnologia e cultura. Tratava-se de incentivar a construção de um currículo organizado não apenas em torno de disciplinas, mas também de situações, tempos e espaços diversos favoráveis à iniciativa, à autonomia e à atuação social dos jovens. Na mesma linha, em maio de 2011 foi aprovado o Parecer CNE/CEB nº 5/2011, que estabeleceu novas diretrizes curriculares especificamente para o ensino médio, apontando que:

(...) a organização curricular do ensino médio deve oferecer tempos e espaços próprios para estudos e atividades que permitam itinerários formativos opcionais diversificados, a fim de melhor responder à heterogeneidade e pluralidade de condições, múltiplos interesses e aspirações dos estudantes, com suas especificidades etárias, sociais e culturais, bem como sua fase de desenvolvimento. (Parecer CNE/CEB $n^{\circ}$ 5/2011 - Diretrizes Curriculares Nacionais do Ensino médio).

Indica-se a necessidade de ampliar o diálogo com os pertencimentos e estranhamentos dos jovens do ensino médio, orientando as estratégias 
de aulas de História para leituras plurais do passado. O patrimônio e a memória constituem bons temas para o debate e a reflexão sobre o passado quando se entende a memória como campo de lutas políticas e culturais. São assuntos provocativos para a pesquisa nas aulas de História, campo de possibilidades para ensiná-la tomando como inspiração métodos e técnicas do fazer histórico: formular hipóteses, classificar fontes históricas, iniciar o aluno na explicação histórica. Assim, ensinar História passa a ser ensinar a fazer história, de modo que os alunos aprendam como se produz o conhecimento histórico e que o passado pode ser analisado segundo muitos pontos de vista (Meneses, 2000).

A pesquisa em História poderá também colocar os jovens em contato com o patrimônio documental, experiência que se anuncia como profícua pela curiosidade que provoca nos alunos. As observações de Corso (s.d.), após vivenciar com seus alunos uma experiência no Arquivo Público do Rio Grande do Sul, são interessantes para pensar as questões aqui apresentadas:

\begin{abstract}
No momento em que os alunos entram no prédio do arquivo que abriga milhões de documentos, acontece o primeiro estranhamento. O prédio que foi especificamente planejado para comportar tamanha documentação chama bastante atenção dos alunos. São os documentos assim tão importantes que necessitem ser guardados em um determinado lugar, com tantos cuidados?
\end{abstract}

O contato dos jovens com o patrimônio documental é importante para que compreendam a complexidade da construção do conhecimento histórico. Um aluno em uma das oficinas do Arquivo Público do Rio Grande do Sul disse: "agora eu sei como é feito um livro de História". Aproximar o ensino da História dos procedimentos do historiador torna a pesquisa imprescindível e, quem sabe, uma possibilidade de envolver os jovens com a potência dessa disciplina: compreender o presente.

Para pensar o patrimônio no currículo escolar, recomendado por pareceres e resoluções, imaginamos o movimento de fios que compõem uma trama tecida. O patrimônio dado como saberes, formas de expressão, celebrações, lugares e produtos materiais frutos da criação de homens e mulheres em tempos e espaços diferentes pode também constituir um dos fios que puxa outros e forma sentidos para o presente e o passado.

Na configuração de que o patrimônio vai muito além do artístico, dos objetos e dos prédios, valorizando também a relação da sociedade com a sua cultura, é fundamental compreendê-lo como parte da vida cotidiana. Para Canclini (1994), o patrimônio cultural é o que um conjunto social considera como sua cultura e o que o diferencia de outros grupos. Mais do que monumentos históricos, edificações, objetos e outros bens materiais, envolve também a experiência condensada em saberes e fazeres, os modos de usar e os espaços físicos. Tudo isso sintetiza a forma como determinados grupos sociais concebem a vida e o mundo. O patrimônio possibilita que o professor foque também espaços e práticas importantes para os jovens estudantes do ensino médio. E isso não significa transformar as aulas de História em palco de reconhecimento e pertencimento. Ao contrário, pode 
sim provocar a curiosidade pelo estranhamento de diferentes concepções de patrimônio que pautam os critérios de seleções dos países orientais, por exemplo. No Japão, a permanência dos objetos é menos importante do que o conhecimento para produzi-los. Hartog (2006) comenta sobre o santuário d'Ise, reconstruído de forma idêntica a cada 20 anos, o que evidencia uma lógica que não busca a manutenção da visibilidade desses monumentos religiosos, mas o saber ou a técnica de produção dos templos de madeira.

É necessário instigar o jovem a elaborar hipóteses sobre o que os bens significam para quem os admira hoje. Isso não redunda em ignorar o sentido construído historicamente para determinados patrimônios. Existem obras singulares que sintetizam os desafios enfrentados pela sociedade que os elaborou: fortes motivos para serem preservadas, debatidas e acessadas por todos.

Cabe à História debater a memória, investigar o contexto das escolhas e seleções dos bens protegidos pelas políticas patrimoniais e, principalmente, o porquê de alguns serem destruídos. Quem participa dessas escolhas? Quem está representado nas indicações? Quem está ausente? Quais as diferentes identidades em face do patrimônio? Por que certos objetos são favoritos e definidos como mais relevantes do que outros para a construção de uma imagem oficial da Nação?

Ouro Preto foi a primeira cidade a receber o reconhecimento de patrimônio brasileiro, numa referência não só à arte barroca, mas também ao palco da construção da imagem de Tiradentes como "herói" nacional. Não por acaso o nome de Tiradentes é o primeiro inscrito no livro de aço (Livro dos Heróis da Pátria) em que estão elencados os nomes de personagens históricos que, por determinação legal, foram elevados à condição de heróis nacionais. O livro encontra-se hoje no Panteão da Liberdade e da Democracia Tancredo Neves (Panteão da Pátria), localizado em Brasília.

O patrimônio era visto como uma pedagogia pública para ensinar aos brasileiros sobre seu passado e, igualmente, instituí-lo. Os bens patrimoniais deveriam ser preservados e cultuados como objetos que materializavam o passado, tal a vinculação entre patrimônio e nação. Mas o patrimônio não é somente o edificado ou o "de pedra e cal". É necessário compreendê-lo de forma mais ampla, presente nas ruas, nas praças, nas escolas, em nossas casas, nas práticas culturais dos jovens que circulam pelas escolas todos os dias. O professor insere-se nessa questão tanto possibilitando uma abordagem crítica do patrimônio quanto trabalhando com os patrimônios não consagrados pelas políticas públicas, ou seja, com as referências culturais dos jovens estudantes ou de outros povos.

Com esse propósito, entendemos que a sala de aula é espaço para efetivar situações de aprendizagens que instiguem os alunos a observar, identificar e pesquisar os múltiplos sentidos do patrimônio cultural brasileiro. Para isso, podemos nos basear nas categorias que o Instituto do Patrimônio Histórico e Artístico Nacional (Iphan)/Ministério da Cultura (MinC) utiliza em seus trabalhos de identificação e reconhecimento do patrimônio brasileiro: 
- Os lugares: feira, casa, praça, parque, rua, cachoeira, lagoa, rio, sítio arqueológico, centro da cidade, construção antiga, igreja etc.

- As celebrações: festas dos santos padroeiros, festividades dos terreiros de candomblé, comemorações das datas históricas ou relacionadas à agricultura, festas que marcam rituais de alguns povos indígenas etc.

- As formas de expressão: música, dança, teatro, literatura, causos, pinturas, esculturas, cantigas de trabalho, línguas indígenas, dialetos, sotaques etc.

- Os saberes: receita de uma comida, técnica especial para produzir algo ou tocar um instrumento musical, um jeito de quebrar coco, fazer queijo e farinha, garimpar, construir uma casa de taipa ou madeira, cultivar a mandioca etc.

Esse conjunto foi levado em conta pelas políticas públicas a partir do Decreto $n^{0} 3.551 / 2000^{13}$, que confere reconhecimento às expressões culturais por muito tempo ignoradas. O entendimento plural do conceito de patrimônio incita a pensá-lo para além dos bens consagrados pelas políticas de preservação, uma vez que a história de uma cidade, por exemplo, é feita por seus bens materiais e naturais, mas, principalmente, pela vida que acontece, seja em bairros operários, em áreas nobres ou nas vilas, sendo fundamental a ideia de que o patrimônio existe nos museus, nos centros culturais, na cultura produzida por determinados grupos ou, como se considera recentemente, nos conhecimentos e tradições de grupos indígenas e afro-brasileiros.

As diferentes expressões da cultura juvenil podem ser estudadas como um patrimônio não consagrado, parte da vida dos grupos juvenis que circulam pelas escolas. A própria Unesco tem considerado os jovens como sujeitos de ações patrimoniais. O Fórum Juvenil do Patrimônio Mundial e o Fórum Juvenil Ibero-Americano do Patrimônio Mundial são espaços que legitimam os jovens como atores políticos e sociais, capazes de influenciar, por meio da participação, importantes processos de transformação no cenário das políticas públicas de cultura. Destaca-se o documentário Sou Jovem, meu patrimônio é o Mundo, ${ }^{14}$ resultado do Fórum Juvenil do Patrimônio Mundial de 2010.

De maneira mais ampla, para além do nacional, pensamos no patrimônio genético que acentua não somente a conservação dos recursos do planeta, mas os modos de vida e os conhecimentos tradicionais de populações que são alvo da biopirataria que alimenta o mercado mundial de produtos biotecnológicos. É uma soma de questões interdisciplinares para discutir a manipulação de material genético; a tensão entre o uso coletivo dos conhecimentos tradicionais e seu uso na indústria farmacêutica e de cosméticos; os processos de clonagem; a titularidade da propriedade genética e as questões éticas, políticas e religiosas; a relação que se estabelece entre grupos indígenas e grandes empresas que tentam patentear conhecimento tradicional de uso coletivo; as lutas do MST e da Via Campesina contra as empresas transnacionais que modificam produtos

\footnotetext{
13 O Decreto no 3.551/2000 instituiu o Registro de Bens Culturais de Natureza Imaterial em quatro livros: I - Livro de Registro dos Saberes, inscritos conhecimentos e modos de fazer enraizados no cotidiano das comunidades; II - Livro de Registro das Celebrações, inscritos rituais e festas que marcam a vivência coletiva do trabalho, da religiosidade, do entretenimento e de outras práticas da vida social; III - Livro de Registro das Formas de Expressão, inscritas manifestações literárias, musicais, plásticas, cênicas e lúdicas; IV - Livro de Registro dos Lugares, inscritos mercados, feiras, santuários, praças e demais espaços onde se concentram e reproduzem práticas culturais coletivas. Em 2012, o Brasil contava com 25 bens registrados nesses livros.

${ }^{14}$ Disponível no Youtube.
} 
agrícolas e sementes a fim de gerar dependência externa em pequenos agricultores, entre tantos outros temas.

Em caráter provisório, é possível afirmar que há desafios que se impõem todos os dias aos educadores que atuam com os jovens nas escolas de ensino médio, dos quais se destaca aprender a lidar com a diversidade e provisoriedade que nos cerca. Não é fácil, sabemos! Nessa perspectiva, como ensinar História aos jovens? Ficamos com as palavras de Mário Chagas (2004, p.144): "interessa pensar a educação como alguma coisa que não se faz sem se ter em conta um determinado patrimônio cultural e determinados aspectos da memória social (...)". Uma educação aberta à criação.

\section{Considerações finais}

O ensino de História, mais uma vez, é colocado em xeque, na medida em que as mudanças propostas e a nova realidade social e cultural, na qual está inscrito o ensino médio, exigem da docência uma tomada de decisão em relação ao que se revela como fundamental na organização do currículo e na seleção dos conteúdos para esse nível de ensino. O professor de História deve pensar o seu exercício profissional no interior de uma discussão que não pode deixar de levar em conta a pesquisa como prática superior de aprendizagem conceitual; o tema da juventude e dos seus modos de vida como elementos diferenciadores das relações dos jovens com a escola, com a própria história e com a questão do patrimônio, este pensado como lugar de aprendizagem sobre a vida das comunidades e a compreensão da história local.

Reafirmamos que o ensino de História pode ser pensado no interior das novas disposições curriculares como aglutinador de outras disciplinas, sobretudo a Geografia e as Ciências Sociais, no sentido de promover a pesquisa como o recorte que põe conceitos em movimento e leva os estudantes não apenas a acumularem conhecimentos históricos, mas a utilizarem uma porção de conceitos para compreender a história do passado e o seu próprio mundo. A construção dessa possibilidade pedagógica não pode deixar de se ater à especificidade de uma juventude que desafia os modos tradicionais de aprender em história e, ao mesmo tempo, precisa de conceitos para refinar sua visão de mundo.

\section{Referências bibliográficas}

300, a ascensão do império. Direção: Zack Snyder. EUA: Warner Bros., 2006. DVD (117 min).

ARGO. Direção Ben Affleck. EUA: Warner Bros., 2012. DVD (120 min). 
BRASIL. Conselho Nacional de Educação (CNE). Câmara de Educação

Básica (CEB). Parecer n 11, de 07 de julho de 2010. Diretrizes

Curriculares Nacionais para o Ensino Fundamental de nove anos. Diário

Oficial da União, Brasília, DF, 9 dez. 2010. Seção 1, p. 28.

BRASIL. Conselho Nacional de Educação (CNE). Câmara de Educação Básica (CEB). Resolução n 2, de 30 de janeiro de 2012. Define diretrizes curriculares nacionais para o ensino médio. Diário Oficial da União, Brasília, DF, 31 jan. 2012. Seção 1, p. 20.

BRASIL. Decreto no 3.551, de 4 de agosto de 2000. Dispõe sobre o registro de bens culturais de natureza imaterial que constituem patrimônio cultural brasileiro, cria o Programa Nacional do Patrimônio Imaterial e dá outras providências. Disponível em: < http://www. planalto.gov.br/ccivil_03/decreto/D3551.htm> .

BRASIL. Ministério da Educação (MEC). Secretaria de Assuntos Estratégicos da Presidência da República. Reestruturação e expansão do ensino médio no Brasil: Grupo de Trabalho Interministerial instituído pela Portaria $n^{\circ} 1.189$, de 05 de dezembro de 2007 e Portaria $n^{\circ} 386$, de 25 de março de 2008. Brasília: MEC, 2008. Disponível em: < http:// portal.mec.gov.br/seb/arquivos/pdf/2009/gt_interministerialresumo2. pdf $>$.

BRASIL. Ministério da Educação (MEC). Secretaria de Educação Fundamental (SEF). Parâmetros Curriculares Nacionais: história e geografia. Brasília: MEC/SEF, 1998.

CANCLINI, Nestor García. O patrimônio cultural e a construção do imaginário nacional. Revista do Iphan, Rio de Janeiro, n. 23, p. 94-115, 1994.

CHAGAS, Mário. Diabruras do Saci: museu, memória, educação e patrimônio. MUSAS: Revista Brasileira de Museus e Museologia, Rio de Janeiro, v. 1, n. 1, 2004.

CORSO, Graziele. O uso do documento nas aulas de História na educação básica: uma reflexão a partir da experiência de estágio em Educação Patrimonial. Porto Alegre, [s.d.]. 10 p. Trabalho não publicado.

DAYRELL, Juarez. A música entra em cena: o rap e o funk na socialização da juventude em Belo Horizonte. 2001. 409 f. Tese (Doutorado em Educação) - Programa de Pós-Graduação da Faculdade de Educação, Universidade de São Paulo, São Paulo, 2001. Disponível em: <http://observatoriodajuventude.ufmg.br/publication/a-musicaentra-em-cena-o-rap-e-o-funk-na-socializacao-da-juventude-em-belohorizonte/wppa_open/>. 
FABBRINI, Anna; MELUCCI, Alberto. A idade de ouro. São Leopoldo: Ed. Unisinos, 2004.

GOULART, Oroslinda Maria Taranto; SAMPAIO, Carlos Eduardo Moreno; NESPOLI, Vanessa. O desafio da universalização do ensino médio. Brasília: Instituto Nacional de Estudos e Pesquisas Educacionais Anísio Teixeira, 2006. (Série Documental. Textos para Discussão, 22).

HARTOG, François. Tempo e patrimônio. Varia Historia, Belo Horizonte, v. 22, n. 36, p. 261-273, jul./dez. 2006.

INSTITUTO BRASILEIRO DE GEOGRAFIA E ESTATÍSTICA. Contagem populacional. Pesquisa Nacional por Amostra de Domicílio: indicadores sociais. Brasília: IBGE, 2011. Disponível em: < http://www.ibge.gov. br/home/estatistica/populacao/condicaodevida/indicadoresminimos/ sinteseindicsociais2012/default.htm $>$.

KUENZER, Acacia Zeneida. O ensino médio no Plano Nacional de Educação 2011-2020: superando a década perdida? Educ. Soc., Campinas, v. 31, n. 112, p. 851-873, jul./set. 2010. Disponível em: $<$ http://www.cedes.unicamp.br>.

LE GOFF, Jaques. História e memória. 5. ed. Campinas: Ed. da Unicamp, 2003.

MELO, José Ernesto. "Seu futuro passa por aqui": o ENEM como política avaliativa e os conhecimentos históricos exigidos. Aedos. v. 4, n. 11, set. 2012. Disponível em: < http://seer.ufrgs.br/aedos/article/ view/31069>.

MENESES, Ulpiano T. Bezerra de. Educação e museus: sedução, riscos e ilusões. Ciências \& Letras:. Revista da Faculdade Porto-Alegrense de Educação, Ciência e Letras, Porto Alegre, n. 27, jan./jun. 2000.

MOEHLECKE, Sabrina. O ensino médio e as novas diretrizes curriculares nacionais: entre recorrências e novas inquietações. Revista Brasileira de Educação, Rio de Janeiro, v. 17, n. 49, jan./abr. 2012.

PEREIRA, Nilton Mullet; SEFFNER, Fernando. História, leitura e escrita no ensino médio. In: PEREIRA, Nilton M. et al. Ler e escrever: compromisso no ensino médio. Porto Alegre: Ed. da UFRGS, 2008.

PRATS, Joaquín. Ensinar história no contexto das ciências sociais: princípios básicos. Revista Educar, Curitiba, p. 201-204, 2006.

RAMOS, Francisco Régis Lopes. Uma questão de tempo: os usos da memória nas aulas de História. Caderno CEDES [online]. v. 30, n. 
82, p. 397-411. 2010. Disponível em: < http://www.scielo.br/scielo. php?script $=$ sci_arttext\&pid $=$ S0101-32622010000300009>.

SOU jovem, meu patrimônio é o mundo. Produção coletiva de jovens do Fórum Juvenil do Patrimônio Mundial. 34ª sessão do Comitê do Patrimônio. 2010 (15 min). Disponível em: <http://www.youtube.com/ watch?v=fvDSugY79lM $>$.

SPOSITO, Marília Pontes. Considerações em torno do conhecimento sobre juventude na área de educação. In: . Juventude e escolarização. Brasília: Inep, 2001. (Série Estado do Conhecimento).

WAISELFISZ, Julio Jacobo. Mapa da violência 2012: a cor dos homicídios no Brasil. Rio de Janeiro: Cebela, Flacso; Brasília: SEPPIR/PR, 2012.

ZIBAS, Dagmar M.L. Refundar o ensino médio? Alguns antecedentes e atuais desdobramentos das políticas dos anos de 1990. Educ. Soc., Campinas, v. 26, n. 92, p. 1067-1086, Especial - out. 2005. Disponível em: <http://www.cedes.unicamp.br>.

Nilton Mullet Pereira, doutor em Educação pela Universidade Federal do Rio Grande do Sul (UFRGS), é professor do Programa de Pós-Graduação em Educação da UFRGS, Porto Alegre, Rio Grande do Sul, Brasil.

niltonmp.pead@gmail.com

Fernando Seffner, doutor em Educação pela Universidade Federal do Rio Grande do Sul (UFRGS), é professor do Programa de Pós-Graduação em Educação da UFRGS, Porto Alegre, Rio Grande do Sul, Brasil.

fernandoseffner@gmail.com

Carmem Zeli Gil, doutora em Educação pela Universidade Federal do Rio Grande do Sul (UFRGS), é professora da área de Ensino de História da Faculdade de Educação da UFRGS, Porto Alegre, Rio Grande do Sul, Brasil. carmemz.gil@gmail.com

Carla Meinerz, doutora em Educação pela Universidade Federal do Rio Grande do Sul (UFRGS), é professora da área de Ensino de História da Faculdade de Educação da UFRGS, Porto Alegre, Rio Grande do Sul, Brasil. carlameinerz@gmail.com

Recebido em 27 de junho de 2013.

Aprovado em 3 de dezembro de 2013. 